\title{
The Impact of Resettlement Program on Livelihoods of Indigenous Community, the Case of Esira District in Dawuro Zone, SNNPRS
}

\author{
Markos Mamude ${ }^{1}$, Girma Alemu ${ }^{2}$ \\ ${ }^{1}$ Department of Geography and Environmental Studies, Mizan-Tepi University, Mizan, Ethiopia \\ ${ }^{2}$ Department of Geography and Environmental Studies, Jimma University, Jimma, Ethiopia
}

Email address:

Markosmamude2009@gmail.com (M. Mamude)

\section{To cite this article:}

Markos Mamude, Girma Alemu. The Impact of Resettlement Program on Livelihoods of Indigenous Community, the Case of Esira District in Dawuro Zone, SNNPRS. International Journal of Economy, Energy and Environment. Vol. 6, No. 3, 2021, pp. 71-75. doi: $10.11648 /$ j.ijeee.20210603.12

Received: March 30, 2021; Accepted: June 26, 2021; Published: July 13, 2021

\begin{abstract}
Resettlement program is a measure taken to reduce the problems of food insecurity and household income diversification. However, improper implementations of the program have negative impact on socio-economic and environmental related issues particularly natural resource degradation which causes LU/LC change in the study area. In the context Ethiopian, resettlement has been carried out both voluntary and involuntary nature. Voluntary resettlement program occurred with the individual interest without any external influences, whereas involuntary is related with massively implemented through government policy. This study was carried out to analyze impact of resettlement program on livelihood of indigenous community in Esira district, Dawuro zone. The livelihood strategies of indigenous community before and after resettlement program where assessed using questionnaire, key informant interviews and filed observations. The finding of this study shows that, after resettlement program the indigenous community faces the problems of access to communal resource utilizations such as common grazing area and Forest, limitation of cattle number, limited annual source of income and shifting of economic activates. On other, the resettlement program brought positive impacts for indigenous community by introducing some of fruits like avocado, mango, banana and ginger which is not familiar before the resettlement program in the study area. Based on finding, it is recommended that well planned resettlement program by considering the existed indigenous community and the newly settler through mutual benefit natural resource.
\end{abstract}

Keywords: Resettlement, Indigenous Community, Livelihood, Common Resource

\section{Introduction}

The food insecurity is an outcome of rapid population growth, limited land holding size, landlessness and environmental degradation. To improve this situation, governments have planned resettling affected populations to relatively fertile and secure areas of the country [11].

Resettlement program is a measure taken to reduce the problems of food security in the areas of population pressure on resource utilization. It can be spontaneous or planned movement of people from their original dwelling to resettle in a new area where they have to adapt to the social, biophysical, human and administrative system of the new environment [1].
Due to socio-economic, environmental and political situations people displaced in different parts of the world. According to [10] report, the movement of people from place to place has continued rapidly. Africa countries like Kenya, Tanzania, Sudan, Ghana, Senegal, Burkina Faso, Egypt and Ethiopia has practice planned resettlement. While, several of these schemes done to improve the well-being of resettled community in general and the efforts have unsuccessful expectation. These expectations themselves may have been unrealistically high in many cases [8].

Ethiopian government has also considered resettlement as one of measure to reduce the chronic food insecurity problem and to minimize population pressure on land use. The cause for food insecurity is due to land degradation, followed by 
drought, famine, small farm land size and landlessness. As a result, millions of population had faced food insecurity problems for the past decades [9]. Resettlement programs in Ethiopian have close relation with country's land tenure policies, in which land belongs to the state and smallholders' representation in resource governance is limited [3].

In South nation nationality and people regional state (SNNPRS) government implemented the program as a solution to tackle the problem of food insecurity.

Resettlement program in Esira district also resulted reshaping peoples' access to natural resource as well as a change in livelihood strategies. Specifically, such change occurs in patterns of land use, land tenure, access to communal grazing land, environmental impacts such as large areas of forest and grass lands were cleared to construct house, social service and distributed land for settlers. Before the resettlement scheme some kebeles where covered with forest. The indigenous communities use this forest as sources of income in bee-keeping, collecting spices, wild fruits and timber production. After the resettlement program, these forests were cleared and the land was distributed to settlers. It also failed to adapt farming practices to the agro ecological conditions of the area and eventually resulted in change of household livelihood strategies [6].

\section{Description of Study Area}

The present study was carried out in Esira District in Dawuro zone which is located in Southern Nation Nationality and People Regional State (SNNPRS). Latitudinal and longitudinal extent of Esira district is located between $6^{\circ} 57^{\prime}$ $00^{\prime \prime}$ to $7^{\circ} 04^{\prime}$ North and $36^{\circ} 02^{\prime}$ up to $37^{\circ} 16^{\prime}$ east respectively. The topography of the Esira district includes different physical features like valley, plain, hills and mountain. The elevation of the district varies from $549 \mathrm{~m}$ to $2443 \mathrm{~m}$ above the sea level. The mean annual temperature varies from 17.6 to $27.5^{\circ} \mathrm{C}$ and the average annual rainfall varies between 1401 and $1800 \mathrm{~mm}$. The short rainy season is between February and March while, long rainy season is between May and September. According to FAO soil classification, dystricnitisol is the dominant soil followed by orthic-acrisol and eutric-cambisol. The livelihood strategy of study area was based on mixed (crop production with livestock husbandry) [6].

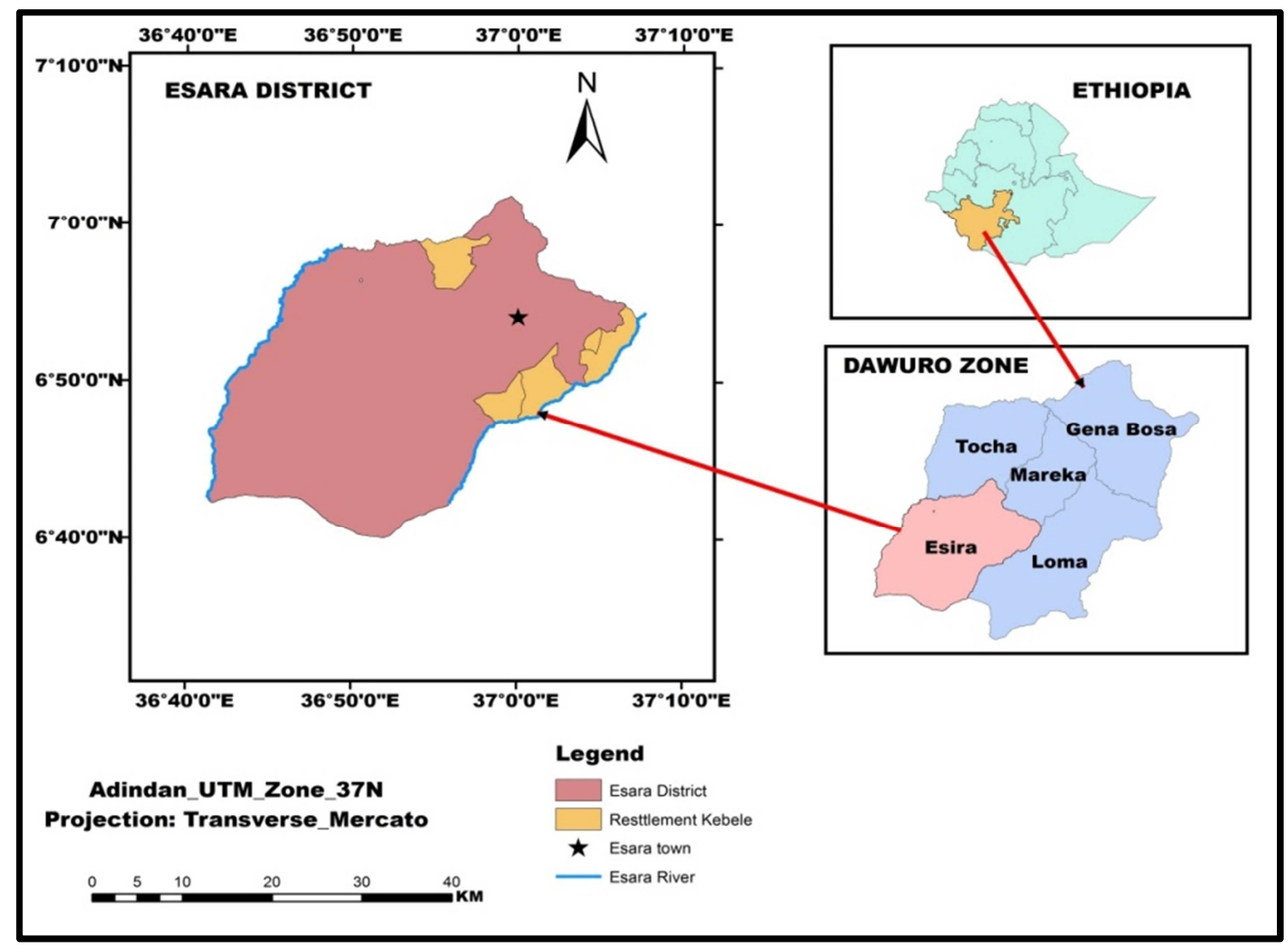

Figure 1. Map of Study area.

\section{Methods of Data Collections and Analysis}

This study was based on explanatory sequential approach of mixed research design. This is because the study was used both quantitative and qualitative data to analysis the resettlement impact on livelihood strategies of indigenous community in study area. In this study, both the primary and the secondary data collection techniques were used. The primary data was collected through questionnaires, key 
informant interview (KII) and field observation. While secondary data were collected from written documents, annual reports of concerned office.

The collected data was interpreted using descriptive statistics; frequencies, percentage and figure in order to easily interpretation and quick visual comparisons of the resettlement impacts within the study area.

\section{Result and Discussion}

Resettlement program in Ethiopia is closely related with the deterioration of livelihoods of the rural community and the less agricultural productivity in the traditionally settled areas [2]. The program is one of the social manifestations which can be essential as part of large projects. However, different scholars argue that forced resettlement or relocation results into high magnitude of social and economic challenge [5]. Therefore, this section presents both positive and negative consequences of resettlement as follows:

\subsection{Livelihood Strategies of Indigenous Community in Esira District}

Livelihood strategy is an organized ways of lifestyle choices, goals, values, and activities which is influenced by biophysical, political, economic, social and cultural components [4]. Agriculture which includes crop production and animal husbandry is one of the dominant livelihood activates before resettlement program. However, the type of agricultural practice is highly depends on the size of land holding. As presented below table 1, Aagriculture constitutes the highest share $(75.6 \%)$ before resettlement program while trade share largest percentage $(45.1 \%)$ after resettlement program this is because of limitation of land holding size and conversations of bare land to other land use class after resettlement program.

Table 1. Livelihood Activities of rural community in study area.

\begin{tabular}{lllll}
\hline \multirow{2}{*}{$\begin{array}{l}\text { Livelihood } \\
\text { Activity }\end{array}$} & \multicolumn{2}{c}{ Before Resettlement } & \multicolumn{2}{c}{ After Resettlement } \\
\cline { 2 - 5 } & Frequency & $\mathbf{\%}$ & Frequency & $\mathbf{\%}$ \\
\hline Agriculture & 62 & 75.6 & 24 & 29.3 \\
Trade & 8 & 9.8 & 37 & 45.1 \\
Hand craft & 12 & 14.6 & 21 & 25.6 \\
Total & 82 & 100.0 & 82 & 100.0 \\
\hline
\end{tabular}

Source: Field survey, 2020

\subsection{Access to Communal Resource (Forest and Grazing Area)}

The ultimate goal of resettlement is to ensure and assist people to advance socio- economic potential in order to improve their incomes and living standards [2]. However, before the implementation the program, Collection of firewood, charcoal and timber production is an important livelihood strategy that supports household income mainly for indigenous communities who have no other source of income. As indicated below the table $2(58.5 \%)$ of selected respondents explained that before the resettlement the access to natural resource such as grazing area and forest is high. However, after resettlement program (76\%) of respondent replayed that, low access to communal grazing land and forest products and (14.6\%) replied medium access to common properties resource. Those respondents who have medium access are especial cause of proximity to the resource.

Table 2. Access to common properties.

\begin{tabular}{lllll}
\hline \multirow{2}{*}{$\begin{array}{l}\text { Resource } \\
\text { access }\end{array}$} & \multicolumn{2}{c}{ Before resettlement } & \multicolumn{2}{c}{ After resettlement } \\
\cline { 2 - 5 } & Frequency & $\mathbf{\%}$ & Frequency & \% \\
\hline Low & 10 & 12 & 62 & 75.6 \\
Medium & 24 & 29.2 & 12 & 14.6 \\
High & 48 & 58.5 & 8 & 9.7 \\
Total & 82 & 100 & 82 & 100.0 \\
\hline
\end{tabular}

Source: Field survey, 2020

\subsection{Households Livestock Grazing Area}

According to [7] as government point of view, the voluntary resettlement program has resulted in reducing population of pressure on natural resources at the origin of the resettles and consequently allowing the natural resource degradation in newly settled areas. In study area, livestock production plays an important role in supporting rural economy before the implementation of the grogram. However, after resettlement program animal keeping is affected by land cover change. The ingenious community keeps different types of animals for example, cattle, goat, sheep and donkey. Source of animal feed before resettlement is communal grazing area that includes grassland, shrub and forest. As explained by elder during interviews shortage of animal feed is important factors for limit number of livestock in the study area. As shown in table 3, out of sampled households $(76.8 \%)$ indicated that, they use communal grazing area before resettlement and after resettlement $(92.7 \%)$ replayed that, they use his/her own land for cattle grazing which have impact on the number of livestock generally and household income particularly.

Table 3. Livestock grazing Area.

\begin{tabular}{lllll}
\hline \multirow{2}{*}{ Grazing area } & \multicolumn{2}{l}{ Before Resettlement } & \multicolumn{2}{l}{ After Resettlement } \\
\cline { 2 - 5 } & Frequency & $\mathbf{\%}$ & Frequency & $\mathbf{\%}$ \\
\hline My own land & 19 & 23.2 & 76 & 92.7 \\
Communal land & 63 & 76.8 & 6 & 7.3 \\
Total & 82 & 100 & 82 & 100 \\
\hline
\end{tabular}

Source: Field survey, 2020

\subsection{Source of Income}

As indicated in the figure below $(72 \%)$ of respondent explained that, there income is based on non-timber production such as in bee-keeping, collecting spices, wild fruits and honey from forest before resettlement program. In addition, about $(22 \%)$ of the sampled households replied that extraction of timber from forest is another source of income for host community before resettlement and the remaining about $(6.1 \%)$ of respondents replied that extraction of charcoal is important activity from forest resource. 


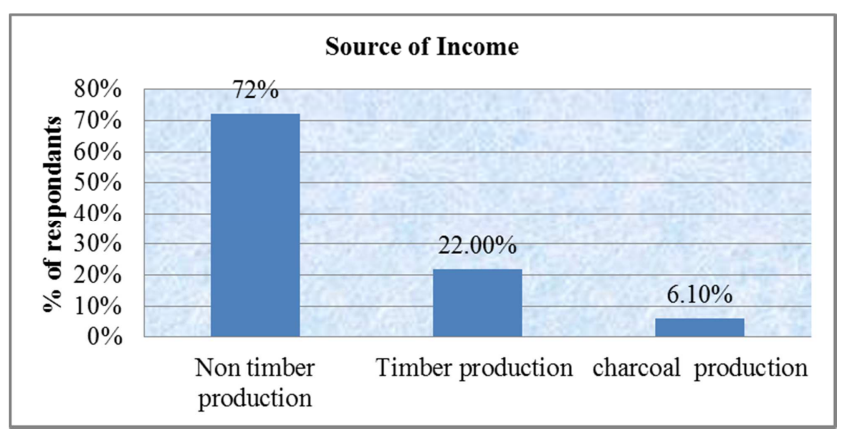

Source: Field survey, 2020

Figure 2. Household income source.

\subsection{Households' Income Per Annual}

According to the table 4 below, about (46\%) of indigenous community indicated that, the annual range of income before resettlement program is between (2501-3500 ETB) and (26\%) of selected respondent replayed that, their annual range of income is between (1501-2500 ETB). As compared the range of household's income in post resettlement $(60 \%)$ of respondents income is between (1501-2500 ETB) and (6\%) of respondents income is between (2500-3500 ETB). This clearly indicates that, there was deviation of income from (2501-3500 ETB) before resettlement to (1501-2500 ETB).

Table 4. Household Income per annual.

\begin{tabular}{lllll}
\hline \multirow{2}{*}{$\begin{array}{l}\text { Income } \\
\text { (ETB) }\end{array}$} & \multicolumn{2}{l}{ Before resettlement } & \multicolumn{2}{c}{ After resettlement } \\
\cline { 2 - 5 } & Frequency & $\mathbf{\%}$ & Frequency & $\%$ \\
\hline$<500$ & 6 & 7 & 11 & 13.4 \\
$501-1500$ & 9 & 11.0 & 13 & 16 \\
$1501-2500$ & 21 & 26 & 49 & 60 \\
$2501-3500$ & 42 & 46 & 5 & 6 \\
$>3500$ & 8 & 10 & 3 & 4 \\
Total & 82 & 100.0 & 82 & 100.0 \\
\hline
\end{tabular}

Source: Field survey, 2020.

\subsection{Positive Impacts of Resettlement for Indigenous Community}

Increase in human settlements has brought about different livelihood opportunities. The interview conducted with community representatives explained that, opportunities which is brought by the resettlement program to indigenous communities is the introduction of some fruits like avocado, mango, banana and ginger which is not familiar before the resettlement program. One of the good opportunities to indigenous community after resettlement is access to social service due to opening of roads in some kebeles like Neda to Sengeti resettlement site. The resettlement program has helped the local people to be benefited from the program in terms of social interactions, provision of improved seeds, and potable water and market access. However, as the positive side of resettlement, its negative sides exceeds more about shortage of farmland for newly born family members in indigenous community, deforestation and shortage of grazing land.

\section{Conclusions and Recommendations}

In Ethiopia the resettlement program have practiced long history of population movement from unproductive and insecure area to more secure and relatively fertile agricultural area. The movement of settlers from origin to new area without proper planning before resettlement program results land use/land cover change in generally and livelihood strategies change in particularly. Land cover change has been considered one of factor that influences the livelihood strategies of rural communities.

Generally, communal grazing land used as source of animal fodder was changed into crop land, built up area after resettlement program. Source of income for indigenous community is the extraction of timber and nontimber from forest. However, this forest is changed into settlement so; it affected poor indigenous community who depends on forest resource. As compared the income of households, majorities of respondents income range is between (2501-3500 ETB) per annual before resettlement is decreased to (1501-2500 ETB) after resettlement program. This implies variation of household income range which causes difficulty in livelihoods of indigenous community. On other side, resettlement brought positive impacts to indigenous community is introduction of some fruits like avocado, mango, banana and ginger which is not familiar before the resettlement program and also access to social service due to opening of roads in some resettlement kebeles. It is better to have well planned resettlement program by considering the existing natural resource and settlement which means resource friendly settlement program which can reduce the stress on the natural environment and improve the livelihood strategies of the indigenous community.

\section{References}

[1] Akpanudoedehe, J. J. (2010). Socio-economic and Cultural Impacts of Resettlement on Bakassi Akpanudoedehe, J. J. (2010). People of Cross River State Nigeria. Unpublished Seminar Paper Presented at the Department of Sociology University of Calabar, Calabar - Nigeria.

[2] Assefa Tolera (2005). Impact on Environment and Host Communities, FSS, Ethiopia.

[3] Chinigo, D. 2015. The politics of land registration in Ethiopia: Territorialising state power in the rural milieu. Review of African Political Economy 42 (144): 174-89. doi: 10.1080/03056244.2014.928613.

[4] Ellis, F. (2000). Rural Livelihoods and Diversity in Developing Countries. New York: Oxford University Press.

[5] Mathur (2006) The Resettlement of People Displaced by Development Projects: Issues and Approach Development, Displacement and Resettlement: Focus on Asian Experience. Vidas Publishing House, New Delhi.

[6] EWARDO (2011). Esira worda Agriculral and rural development office, Annual report 2011. 
[7] Efrem Bechere. (2007). Agricultural and Rural Development in Ethiopia. In the proceedings of International Conference on a Development Strategy of Horn of Africa Rural and Agricultural Development Panel Texas: The University of Texas.

[8] MoARD- Ministry of Agriculture and Rural Development (2009), Resettlement Programm Final food Security Coordination Department, Addis Ababa, Ethiopia (Unpublished document).

[9] Scudder, T. (2005). Agricultural Resettlement, In Colson E. (ed.) Putting People First West view Press, pp 135-200.
[10] UNHCR. 2010). Modelling of organization, services and reception of refugees. Accessd on 10 March, 2014; Available at: http://www.mostproject.Fi/English/about-theproject/resettlement.

[11] WIC (Walta Information Center). 2003. "Ethiopian Population Hits 70.7 Million: The United Nations Population Fund NFPA Calls for Enhancement of Investment in Youth." www.waltainfo.com/EnNews/2003/Oct/08Oct03/Oct08e10.ht $\mathrm{m}$ (Accessed on May 15, 2004).

[12] Workneh, N. (2008). Food security strategy and Productive Safety Net program in Ethiopia In: Forum for Social Studies: Digest of Ethiopia's Policies, Strategies, and Programs. Addis Ababa. 